\title{
Patterns of Injury and Mortality in Pediatric Patients Attending Emergency Department in a Tertiary Care Center in Eastern Nepal
}

\author{
Pramendra Prasad Gupta, ${ }^{1}$ Gyanendra Bahadur Malla, ${ }^{1}$ Rabin Bhandari, ${ }^{1}$ Rosan Prasad Shah Kalawar, ${ }^{2}$ \\ Madan Mandal \\ 'Department of General Practice and Emergency Medicine, B. P. Koirala Institute of Health Sciences, Dharan, Nepal, \\ ${ }^{2}$ Department of Orthopedics, B. P. Koirala Institute of Health Sciences, Dharan, Nepal.
}

\section{ABSTRACT}

Introduction: Trauma is a major and increasing global health concern in the recent world. It is now the leading cause of death among people less than 18 years old. The aim of this study is to analyze all injuries from trauma-related causes among children and adolescents under 18 years old of age.

Methods: This is a retrospective cross sectional study done in Emergency Department of B.P. Koirala Institute of Health Sciences. Patients aged less than 16 years were included with history of trauma from January $1^{\text {st }} 2013$ to $31^{\text {st }}$ December 2013.The details of patient were taken from computerized medical records of the hospital. The demographic data, pattern of injury, mode of injury, diagnosis and outcomes were tabulated in Microsoft Excel.

Results: Total 3958 pediatrics patient were enrolled in this study with Male: Female=3.6:1 and Mean age 9.6 \pm 3.2 years. The common modes of injury were fall injury $2596(65.6 \%)$ and RTAs $1176(29.7 \%)$. Whereas the commonest patters were Fractures 1385 (35\%) and Soft Tissue Injuries 784 (19.8\%).

Conclusions: Fall Injury and Road Traffic Accidents are major and serious problem for children in Low Income countries like Nepal.

Keywords: fractures; injury; pediatric trauma.

\section{INTRODUCTION}

Trauma represents major and increasing global health concern. Historically, infectious diseases have accounted for a majority of childhood morbidity in low and middle-income countries (LMICs). ${ }^{1}$ This trend is transitioning and according to the World Health Organization (WHO), injuries are now the leading cause of death among people ages $1-40 .^{2}$

The WHO reports that 950,000 deaths/year in people less than 18 years of age are attributable to injuries, with $95 \%$ of these deaths occurring in LMICs. Considering the high incidence and diversity of injuries, solving this problem is one of the greatest challenges in the field of public health. ${ }^{2}$ Developing an appropriate approach towards injury prevention in children depends on the knowledge of the epidemiology of trauma.

The aim of this study is to analyze all injuries from trauma-related causes among children and adolescents under 18 years old of age and to determine the prevalence of various types of childhood injuries presenting at BPKIHS.

Correspondence: Dr. Pramendra Prasad Gupta, Department of General Practice and Emergency Medicine, B.P. Koirala Institute of Health Sciences, Dharan, Nepal. Email: dr.pramen@gmail.com, Phone: +977-9852056289. 


\section{METHODS}

This was a retrospective cross-sectional study conducted in department of General Practice and Emergency Medicine at B. P. Koirala Institute of Health Sciences from January 2013 to December 2013. The ethical approval was taken from the Institutional Ethical Review Board at BPKIHS. Convenience sampling technique was used and all pediatrics patients aged less than 16 years were included in this study with history of trauma during the study period.

The details of the patients were taken from computerized medical records and patient files of the hospital. All the data like demographic profiles, patterns of injury, mode of injury and diagnosis were tabulated in Microsoft Excel 2010. The outcomes were recorded as admission in orthopedics ward, discharge from the emergency, left against medical advice (LAMA), admission in Intensive Care unit (ICU) and Death.

Trauma was defined as per American college of Surgeons definition: "Potentially severe physical injury caused by an external source (fall, auto crash, farm or industrial accident, knife or gunshot wound, etc.) that requires emergency medical intervention to attempt to prevent loss of life or limb or substantial, permanent physical impairment. It does not include moderate or minor injuries; heart attacks, strokes, or other internal conditions; chronic, contagious, or infectious diseases; or mental illness not caused by a severe physical injury". Percentage was calculated for the patients sub groups.

\section{RESULTS}

There were total 35,254 patients who attended the Emergency at BPKIHS during the study period. Among them $3958(11 \%)$ pediatric patients had trauma. The male to female ratio was 3.6:1 (Table 1). The mean age was 9.6 years \pm 3.6 years. The age wise distribution (Figure 3), in which majority of cases belonged to age group 5 to 10 years. Among the patients enrolled in the study most of the cases were from Sunsari district followed by Jhapa and Morang (Table 1).

Regarding the mode of injury, most of the cases were due to fall injury either during playing or from height in home or from tree. After fall injury second most common mode were Road traffic accident (RTA) followed by physical assault (Table 2). Regarding the pattern of injury most cases presented were with fractures 1385 (35\%) and soft tissue injuries 784 (19.8\%). Fractures were common to all age groups whereas all cases of head traumas were in age group of 5 to 10 years. Among all the fracture cases most of the cases had upper limb fractures followed by lower limb fractures (Table 2).
Table 1. Demographic distribution of study population.

\begin{tabular}{ll}
\hline $\begin{array}{l}\text { Demographic Distribution } \\
\text { 1. Gender Distribution }\end{array}$ & $\mathbf{n}(\%)$ \\
Male & $3103(78.4)$ \\
Female & $855(21.6)$
\end{tabular}

2. Age wise Distribution

$<1$ years

$24(0.6)$

$1-4$ years

$554(14)$

5-10years

$1947(49.2)$

$>10$ years

$1433(36.2)$

\section{Geographical Distribution}

Sunsari

1187 (30)

Jhapa

978 (24.7)

Morang

$689(17.4)$

Saptari

$420(10.6)$

Okhaldhunga

$186(4.7)$

Ilam

115 (2.9)

Taplejung

$111(2.7)$

Sankhuwasabha

$87(2.2)$

Udaypur

$75(1.9)$

Phidim

$59(1.5)$

Siraha

$51(1.3)$

Table 2. Distribution of study population according to injury.

\begin{tabular}{ll}
\hline $\begin{array}{l}\text { Distribution } \\
\text { 1. Modes of Injury }\end{array}$ & $\mathbf{n}(\%)$ \\
Fall & $2596(65.6)$ \\
Road Traffic Accident & $1176(29.7)$ \\
Physical Assault & $67(1.7)$ \\
Accidental Cut & $51(1.3)$ \\
Electrical Injury & $36(0.9)$ \\
Lightening & $32(0.8)$
\end{tabular}

2. Pattern of Injury

Fracture

1385 (35)

Soft Tissue Injury

784 (19.8)

Bruises/Lacerations

534 (13.5)

Cut Injury

$518(13.1)$

Blunt Trauma Abdomen

$321(8.1)$

Head Injury

$190(4.8)$

Eye Injury

115 (2.9)

Nasal Injury

$99(2.5)$

Penetrating Injury

$12(0.3)$

3. Site of Fracture

$\mathrm{n}=1385$

Upper Limb Fracture

711 (51.3)

Lower Limb Fracture

493 (35.6)

Rib Fracture

109 (7.9)

Pelvic Fracture 
Gupta et al. Patterns of Injury and Mortality in Pediatric Patients Attending Emergency Department in a Tertiary Care Center in ...

Supra-condylar fractures 263 (37\%) were most common fractures found in upper limb injuries followed by both bone fracture $199(28 \%)$ and then medial epicondylar fractures 171 (24\%). Among lower limb injury, most common were Femur fracture 202 (41\%) followed by distal tibial fracture and pelvic bone fracture 72 (5.2\%).

Among the study population 2636 (66.6\%) cases were discharged from Emergency after treatment like closed reduction and Pop cast application. Thirty-two percentage cases were admitted in orthopedics ward that needed open reduction and internal fixation. Among them 90 (7\%) needs immobilization under supervision. Among all cases involved in the study $40(1 \%)$ died, in them most cases were head injury (Table 3 ).

\begin{tabular}{|ll|}
\hline Table 3. Outcomes Variables. \\
\hline Outcomes & $\mathbf{n}(\%)$ \\
Discharged & $2636(66.6)$ \\
Admitted & $1282(32.4)$ \\
ICU & - \\
Death & $40(1)$ \\
\hline
\end{tabular}

\section{DISCUSSION}

The prevalence of trauma in childhood patients was approximately $11 \%$ among the total admission of emergency. This was probably due to delayed presentation to our tertiary institute (either via referrals or direct admission), or probably due to lack of knowledge and low literacy levels among the parents of these children. Other reason behind it might be due to admission in other hospitals or private health care centers. Sharma et $\mathrm{al}^{1}{ }^{1}$ reported a prevalence of $19.23 \%$, Tandon et $\mathrm{al}^{3}{ }^{3}$ reported a prevalence of $14.2 \%$, and another study done at Naraingarh, India, reported a prevalence of $5.5 \%$. $^{3}$

Many studies have been done from Bangladesh, Iran, Nigeria, and from major Indian cities, and these studies have found boys to be more commonly injured then girls. The result in our study was consistent with the findings. Male to female ratio was 3.6:1 in our study which is similar to the $1.9: 1$ to $3.4: 1$ ratio reported in the above studies. School-going children (5-10 years) were the most common age group found to be affected in our study, which is also similar to that reported in other previous studies. ${ }^{4-6}$ The general predominance of boys is probably a combination of biological factors and social, gender-related differences related to activity and risk taking. The mean age of presentation in our study was 9.6 years (SD $=3.6$ years) which is in consonance with the studies done by Osifo et al. ${ }^{7}$ While in study by Sharma et al, ${ }^{1}$ mean age was 6.3 years. This is the most common age groups for school going and playing outside independently. ${ }^{1}$
Majority of our injuries occurred at home, followed by road and school/playground. Studies from Trinidad and Tobago, Ethiopia, and Nigeria, all found the home environment to be the most common place for a childhood injury to occur. ${ }^{7}$ In our study, falls were the leading cause of trauma in all age groups, followed by RTAs which is in consistent with other studies. The injury related to sports activity was included in falls. The number of patients injured due to lightening is surprisingly high in our study with compare to other studies that is probably due to the geographic location of Dharan and its neighboring, which are prone areas for lightening.

Fractures of limbs were the most common pattern of injury in or study followed by soft tissue injury, lacerations and cut injuries. Most of the cases of fracture were due to fall and sports injury reason behind it could be due to outstretching of upper limbs during fall which is common. The study by Sharma et al, ${ }^{1}$ also found orthopedic injuries as most common pattern and finding is also consistent with the study by Bayreuther et $\mathrm{al}^{4}{ }^{4}$ in UK while in a study Loon et $a l,{ }^{5}$ in Malaysia the most common pattern was soft tissue injury. Studies by Krauss et $\mathrm{al}^{10}{ }^{10}$ \& Kirsch et al, ${ }^{14}$ found laceration to be the most common pattern of injury.

The study showed that epidemiology varies regarding the pattern of injuries. ${ }^{1,4-13}$ As study done by Chawdhury et $\mathrm{al}^{15}$ this study also revealed burns \& electrical Injury $(0.9 \%)$ as one of the causes of childhood injury. ${ }^{14}$ Childhood injury by electrocution occurs when children are playing near electric equipments or near fire materials. The injury occurs either due to faulty apparatus, or a lack of understanding of the potential dangers involved. Thus environmental modification along with proper supervision of the younger children is recommended for the prevention of electrocution. ${ }^{14-15}$

Most of the cases in our study were discharged after treatment from emergency ward and about one-third of the cases were admitted and this result is comparable to findings of other studies. The mortality in our study is about one percent that is less $(6.4 \%)$ compared to finding by Sharma et al, ${ }^{1}$ and more $(0.3 \%)$ compared to Kirsch et al. ${ }^{14} \mathrm{ICU}$ admission is zero as mostly all cases were either admitted in wards or referred to other center for ICU admission (due to unavailability of bed in ICU). ${ }^{1,13}$

One limitation of the study is that it involved one center only, so our interpretation of the results only applies to this study population. So, if it would have been done in multiple hospital setting, the better view of epidemiology of pediatric trauma and its major causes and complications would provide a clearer picture of the situation. 


\section{CONCLUSIONS}

Fall injury and Road Traffic Accidents are serious problem for children in Low Income countries like Nepal. We believe the increase in incidence is partly by changes in children's activity pattern over time. Data can be used to identify modifiable risk factors to develop and implement new injury prevention initiatives with the goal of reducing childhood injuries and death.

\section{ACKNOWLEDGEMENTS}

The authors would like to thank Mr. Sunil Parajuli for helping to collect the data from the records.

Conflict of Interest: None.

REFERENCES
1. Sharma M, Lahoti BK, Khandelwal G, Mathur GK, Sharma SS, Laddha A. Epidemiological trends of pediatric trauma: A single-center study of 791 patients. J Indian Assoc Pediatr Surg. 2011 Jul-Sep;16(3):88-92. [Full Text]

2. Nagele P, Hüpfl M, Kroesen G. Epidemiology and outcome of pediatric trauma treated by an emergency-physicianstaffed advanced life-support unit. Wien Klin Wonchenschr. 2004 June;116(11-12):398-403. [Full Text]

3. 3. Tandon JN, Kalra A, Kalra K, Sahu SC, Nigam CB, Qureshi GU. Profile of accidents in children. Indian Pediatr. 1993;30:765-9. [ubMed]

4. Bayreuther J, Wagener S, Woodford M, Edwards A, Lecky F, Bouamra O, Dykes E. Paediatric trauma: injury pattern and mortality in the UK. Arch Dis Child Educ Pract Ed. 2009 Apr;94(2):37-41. [PubMed | DOI]

5. Loon CP, Bruyne J, Chandran PS. P6: Paediatric Trauma: Patterns of Injury Presenting to A Paediatric Trauma And Emergency Unit In A Tertiary Hospital In Malaysia. Malaysian Journal of Pediatrics \& Child Health. 2010;16(2). [Full Text]

6. Buschmann C, Kühne CA, Lösch C, Nast-Kolb D, Ruchholtz S. Major trauma with multiple injuries in German children: a retrospective review. J Pediatr Orthop. 2008 Jan-Feb;28(1):1-5. [PubMed | DOI]

7. Osifo OD, Iribhogbe PE, Ugiagbe EE. Epidemiology and pattern of paediatric and adolescent trauma deaths in a level 1 trauma centre in Benin city, Nigeria. Injury. 2012 Nov;43(11):1861-4. [uued | DOI]

8. Mazurek AJ. Epidemiology of paediatric injury. J Accid Emerg Med. 1994 Mar;11(1):9-16. [MC | Full Text]

9. Zwingmann J, Schmal H, Mehlhorn A, Südkamp NP, Strohm PC Injury patterns in polytraumatized children and consequences for the emergency room management. Acta Chir Orthop Traumatol Cech. 2010 Oct;77(5):365-70. [PMC]

10. Krauss BS, Harakal T, Fleisher GR. General trauma in a pediatric emergency department: spectrum and consultation patterns. Pediatr Emerg Care. 1993 Jun; 9(3):134-8. [PubMed]
11. Nnadi MON, Bankole OB and Fente BG. Epidemiology and treatment outcome of head injury in children: A prospective study J Pediatr Neurosci. 2014 Sep-Dec;9(3):237-41. [PubMed

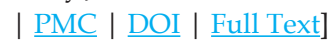

12. Alexandre Fraga AM, Bustorff-Silva JM, Fernandez TM, Fraga GP, Reis MC, Elias Baracat EC, and Coimbra R. Children and adolescents deaths from trauma-related causes in a Brazilian City. World J Emerg Surg. 2013;8:52. [DOI | Full Text]

13. Condello AS1, Hancock BJ, Hoppensack M, Tenenbein M, Stewart TC, Kirwin D, Williamson J, Findlay C, Moffatt M, Wiseman N, Postuma R. Pediatric trauma registries: the foundation of quality care. J Pediatr Surg. 2001 May;36(5):685-9. [uuMed | DOI | Full Text]

14. Kirsch TD, Beaudreau RW, Holder YA, Smith GS. Pediatric injuries presenting to an emergency department in a developing country. Pediatr Emerg Care. 1996 Dec;12(6):411-5. [PubMed]

15. Chowdhury SM, Rahman A, Mashreky SR, Giashuddin SM, Svanström L, Hörte LG, et al. The Horizon of Unintentional Injuries among Children in Low-Income Setting: An Overview from Bangladesh Health and Injury Survey. Journal of Environmental and Public Health. 2009;2009:435403. [DOI]

16. Karbakhsh M, Zargar M, Zarei MR, Khaji A. Childhood injuries in Tehran: A review of 1281 cases. Turk J Pediatr. 2008;50:317-25. [PubMed] 